\title{
QUEEN'S
UNIVERSITY
BELFAST
}

\section{Measurements of fast electron scaling generated by petawatt laser systems}

Tanimoto, T., Habara, H., Kodama, R., Nakatsutsumi, M., Tanaka, K. A., Lancaster, K. L., Green, J. S., Scott, R. H. H., Sherlock, M., Norreys, P. A., Evans, R. G., Haines, M. G., Kar, S., Zepf, M., King, J., Ma, T., Wei, M. S., Yabuuchi, T., Beg, F. N., ... Davies, J. R. (2009). Measurements of fast electron scaling generated by petawatt laser systems. Physics of Plasmas, 16(6), [062703]. https://doi.org/10.1063/1.3155086

Published in:

Physics of Plasmas

Document Version:

Publisher's PDF, also known as Version of record

Queen's University Belfast - Research Portal:

Link to publication record in Queen's University Belfast Research Portal

Publisher rights

(c) 2009 American Institute of Physics.

This work is made available online in accordance with the publisher's policies. Please refer to any applicable terms of use of the publisher.

\section{General rights}

Copyright for the publications made accessible via the Queen's University Belfast Research Portal is retained by the author(s) and / or other copyright owners and it is a condition of accessing these publications that users recognise and abide by the legal requirements associated with these rights.

Take down policy

The Research Portal is Queen's institutional repository that provides access to Queen's research output. Every effort has been made to ensure that content in the Research Portal does not infringe any person's rights, or applicable UK laws. If you discover content in the Research Portal that you believe breaches copyright or violates any law, please contact openaccess@qub.ac.uk. 


\section{Measurements of fast electron scaling generated by petawatt laser systems}

Tsuyoshi Tanimoto, H. Habara, R. Kodama, M. Nakatsutsumi, Kazuo A. Tanaka et al.

Citation: Phys. Plasmas 16, 062703 (2009); doi: 10.1063/1.3155086

View online: http://dx.doi.org/10.1063/1.3155086

View Table of Contents: http://pop.aip.org/resource/1/PHPAEN/v16/i6

Published by the American Institute of Physics.

\section{Related Articles}

Enhancement of Ka emission through efficient hot electron generation in carbon nanotubes on intense laser pulse irradiation

J. Appl. Phys. 112, 053301 (2012)

Temporal evolution of dielectric barrier discharge microplasma

Appl. Phys. Lett. 101, 104101 (2012)

Asymmetric radiative damping of low shear toroidal Alfvén eigenmodes

Phys. Plasmas 19, 082517 (2012)

Simultaneous imaging electron- and ion-feature Thomson scattering measurements of radiatively heated Xe Rev. Sci. Instrum. 83, 10E348 (2012)

Spectral emission measurements of lithium on the lithium tokamak experiment

Rev. Sci. Instrum. 83, 10D537 (2012)

\section{Additional information on Phys. Plasmas}

Journal Homepage: http://pop.aip.org/

Journal Information: http://pop.aip.org/about/about_the_journal

Top downloads: http://pop.aip.org/features/most_downloaded

Information for Authors: http://pop.aip.org/authors

\section{ADVERTISEMENT}

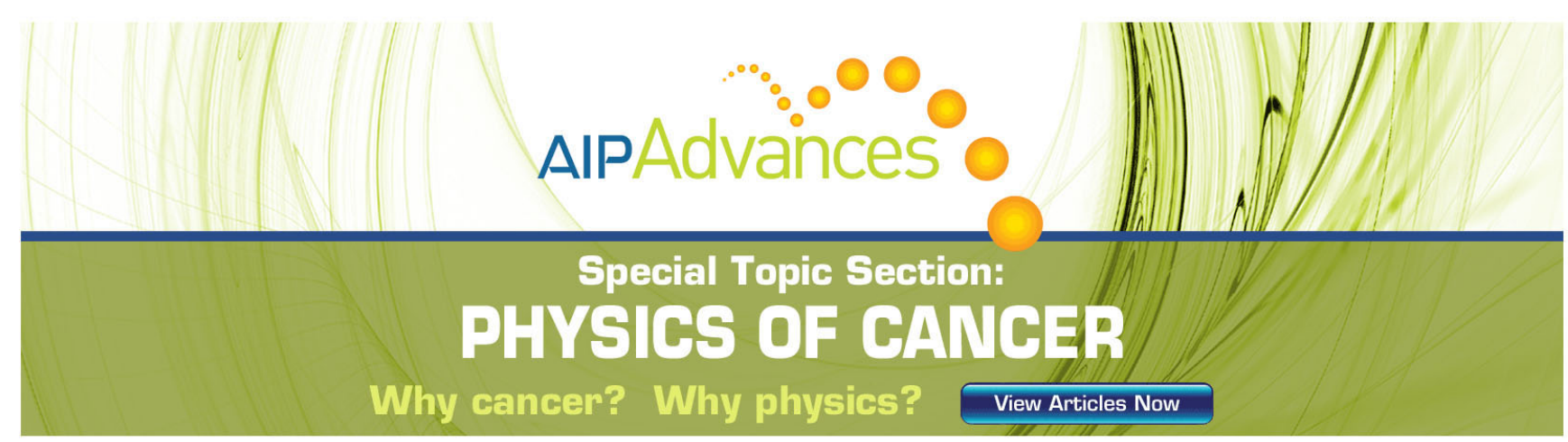




\title{
Measurements of fast electron scaling generated by petawatt laser systems
}

\author{
Tsuyoshi Tanimoto, ${ }^{1}$ H. Habara, ${ }^{1}$ R. Kodama, ${ }^{1}$ M. Nakatsutsumi, ${ }^{1, a)}$ Kazuo A. Tanaka, ${ }^{1}$ \\ K. L. Lancaster, ${ }^{2}$ J. S. Green, ${ }^{2}$ R. H. H. Scott, ${ }^{2,3}$ M. Sherlock, ${ }^{2,3}$ Peter A. Norreys, ${ }^{2,3}$ \\ R. G. Evans ${ }^{3}$ M. G. Haines, ${ }^{3}$ S. Kar, ${ }^{4}$ M. Zepf, ${ }^{4}$ J. King, ${ }^{5}$ T. Ma, ${ }^{5}$ M. S. Wei, ${ }^{5}{ }^{\text {T. Yabuuchi, }}{ }^{5}$ \\ F. N. Beg, ${ }^{5}$ M. H. Key, ${ }^{6}$ P. Nilson, ${ }^{7}$ R. B. Stephens, ${ }^{8}$ H. Azechi, ${ }^{9}$ K. Nagai, ${ }^{9}$ \\ T. Norimatsu, ${ }^{9}$ K. Takeda, ${ }^{9}$ J. Valente, ${ }^{10}$ and J. R. Davies ${ }^{10}$ \\ ${ }^{1}$ Graduate School of Engineering and Institute of Laser Engineering, Osaka University, 2-1 Yamada-oka, \\ Suita, Osaka 565-0871, Japan \\ ${ }^{2}$ STFC Rutherford Appleton Laboratory, Harwell Science and Innovation Campus, Didcot, \\ Oxfordshire OX11 OQX, United Kingdom \\ ${ }^{3}$ Department of Physics, Blackett Laboratory, Imperial College London, Prince Consort Road, \\ London SW7 2BZ, United Kingdom \\ ${ }^{4}$ Centre for Plasma Physics, School of Mathematics and Physics, Queens University Belfast, \\ University Road, Belfast BT7 1NN, United Kingdom \\ ${ }^{5}$ Department of Mechanical and Aerospace Engineering, University of California-San Diego, \\ 9500 Gillman Drive 0411, La Jolla, California 92093-0411, USA \\ ${ }^{6}$ Lawrence Livermore National Laboratory, P.O. Box 808, Livermore, California 94550, USA \\ ${ }^{7}$ Laboratory for Laser Energetics, University of Rochester, 250 East River Road, Rochester, \\ New York 14623, USA \\ ${ }^{8}$ General Atomics Corp., P.O. Box 86508, San Diego, California 92186-5608, USA \\ ${ }_{9}^{9}$ Institute of Laser Engineering, Osaka University, 2-6 Yamada-oka, Suita, Osaka 565, Japan \\ ${ }^{10}$ Groupo Lasers e Plasmas, Centro de Fisica dos Plasma, Instituto Superior Tecnico, Av. Rovisco Pais, 1, \\ 1049-001 Lisbon, Portugal
}

(Received 7 January 2009; accepted 30 April 2009; published online 18 June 2009)

Fast electron energy spectra have been measured for a range of intensities between $10^{18}$ and $10^{21} \mathrm{~W} \mathrm{~cm}^{-2}$ and for different target materials using electron spectrometers. Several experimental campaigns were conducted on petawatt laser facilities at the Rutherford Appleton Laboratory and Osaka University, where the pulse duration was varied from 0.5 to $5 \mathrm{ps}$ relevant to upcoming fast ignition integral experiments. The incident angle was also changed from normal incidence to $40^{\circ}$ in $p$-polarized. The results confirm a reduction from the ponderomotive potential energy on fast electrons at the higher intensities under the wide range of different irradiation conditions. (C) 2009 American Institute of Physics. [DOI: 10.1063/1.3155086]

\section{INTRODUCTION}

The fast ignition (FI) scheme for inertial confinement fusion was first proposed by Tabak et al. ${ }^{1}$ in 1994 and has received considerable world wide interest and attention since then. In the FI scheme, an intense laser pulse (containing many tens of kilojoules of energy in a pulse duration of $\sim$ ten picoseconds) interacts with plasma that has been precompressed to ultrahigh density using nanosecond-duration laser beams. At peak compression of the deuterium-tritium fuel, copious numbers of fast electrons are generated by the interaction between the intense laser light and the plasma at the relativistic corrected critical density surface. These electrons are directed toward compressed plasma core and slowed down and eventually stopped in the dense plasma so that the fast electron energy is transferred to the background plasma. This must occur on a timescale so short that the plasma has little time to respond hydrodynamically. The plasma in the hot spark region is heated to thermonuclear ignition temperatures that eventually generate an off-center fusion burn wave.

The advantage of fast ignition is considerable: The fu-

\footnotetext{
${ }^{a}$ Present address: Laboratoire pour l'Utilisation des Laser Intenses (LULI), CNRS, Ecole Polytechnique, Route de Saclay, 91128 Palaiseau, Cedex F 91128, France.
}

sion gain is much larger than central spark ignition for the same drive energy and the symmetry requirements needed to assemble the fuel to high density are significantly relaxed. Clearly, it is essential to characterize the fast electron energy distribution as a function of irradiance on target. If the average fast electron is too high, then their range is too large in the compressed plasma and more energy is needed to heat the compressed hot spark region. ${ }^{2}$ If the energy of the electrons is too low, then the electrons may not reach the spark region in the compressed matter, as they prone to large angle scattering when they have to traverse dense gold in coneguided geometries. ${ }^{3}$

The fast electrons that can escape the target to spectrometers located some distance away on the target chamber wall represent only a small fraction of the total population that are generated. Those that do escape charge up the target and allow the generation of large electrostatic sheath fields on the front and back of the targets. ${ }^{4}$ The fields are responsible for the acceleration of protons and ions. Nevertheless, it was found in early experiments ${ }^{5-10}$ that the fast electron energy was consistent with ponderomotive scaling of the fast electron energy, as first proposed by Wilks et al. ${ }^{11}$ with some component due to plasma wave generation. ${ }^{12}$ More recently, however, $\mathrm{Chen}^{13}$ reported a discrepancy between the ob- 
served electron spectra (measured in an electron spectrometer with a range between 0.1 and $4 \mathrm{MeV}$ ) and the ponderomotive potential energy, particularly at the highest intensity on target. She reported that the electron temperature was lower than the ponderomotive potential energy there by a factor of 2. The limited number of data points available called for systematic investigation into the behavior of fast electrons escaping the target. In addition, Chen ${ }^{14}$ has also reported a fast electron temperature scaling of $I^{1 / 3}$ from bremsstrahlung radiation measurements of fast electrons entering the target.

Detailed measurements are reported here of the fast electron spectra (those electrons that escaped the target to a magnetic spectrometer located on the chamber wall) in the range of $10^{18}-10^{21} \mathrm{~W} \mathrm{~cm}{ }^{-2}$. The measurements were made on two different petawatt (PW) facilities in the United Kingdom and Japan. The pulse duration was varied from 0.5 to $5 \mathrm{ps}$ and the incident angle and polarization varied from normal incidence to $40^{\circ} p$-polarized. These are in the range that are relevant to fast ignition. The measurements confirm that Chen's observation of a reduction in scaling of the fast electron energy with intensity on target is robust and occurs under a range of irradiation conditions. A simple model that relates the fast momentum and energy conservation is presented that reproduces the data. Nevertheless, new onedimensional Vlasov simulations confirm that the spectrum of fast electron energy entering the target is complex and that the simple model requires cautious application to realistic laser-plasma interactions.

\section{EXPERIMENTAL SETUP}

The experiments were performed using both the VULCAN petawatt (VULCAN PW) (Ref. 15) and GEKKO XII petawatt (GXII PW) laser systems. ${ }^{16}$ The VULCAN PW has a measured intensity contrast ratio of $4 \times 10^{-8}$ and delivered pulses in the range $500 \mathrm{fs}-5 \mathrm{ps}$. Laser pulses with up to $300 \mathrm{~J}$ were delivered on target. The wavelength was $1.054 \mu \mathrm{m}$. The laser was focused onto target using an $f / 3$ parabola and the spot size was $7 \mu \mathrm{m}$ full width at half maximum (FWHM). 20\% of the laser energy was contained within that focal region. ${ }^{17}$ The laser intensity is changed from $10^{18}$ to $10^{21} \mathrm{~W} \mathrm{~cm}^{-2}$ by varying the energy delivered and the pulse duration. The laser was incident at both normal $\left(0^{\circ}\right)$ and $p$-polarized $40^{\circ}$. The GXII PW has a measured intensity contrast ratio of $1.5 \times 10^{-8}$. The pulse duration was between from 0.6 to $0.7 \mathrm{ps}$. Up to $100 \mathrm{~J}$ was delivered on target. The wavelength is $1.053 \mu \mathrm{m}$. The laser was focused onto target using an f/7.6 parabola and the spot size was $15 \mu \mathrm{m}$ FWHM. The laser intensity was from $10^{18}$ to $10^{19} \mathrm{~W} \mathrm{~cm}^{-2}$. The laser was incident at an angle of $26^{\circ}$ to the target normal. ${ }^{18}$

These experiments used a variety of target materials in both single and multilayer structures. The interaction surfaces of target were $\mathrm{Cu}, \mathrm{Au}, \mathrm{Al}$, and $\mathrm{Ti}$ and the target thickness ranged from 5 to $100 \mu \mathrm{m}$. Two different electron spectrometers (ESMs) were used for the fast electron spectrum characterization. Both have been extensively tested and calibrated on other laser-plasma interaction experiments. ${ }^{7,8}$ The

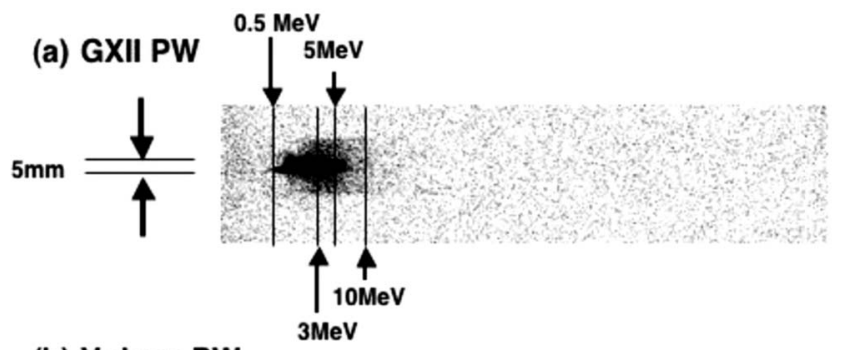

(b) Vulcan PW

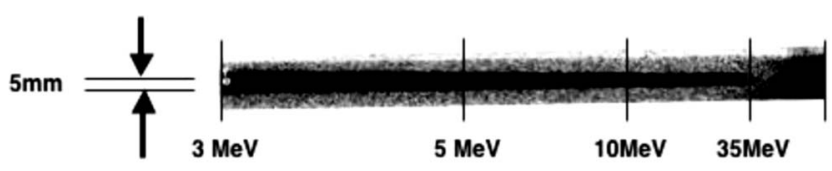

FIG. 1. Raw image plate data taken at (a) GXII PW at Osaka University and (b) the VULCAN PW laser at RAL. In both cases, electron spectrometers were put on the laser axis and the collimator size was fixed at $5 \mathrm{~mm}$. Laser intensities and targets were (a) $6.43 \times 10^{18} \mathrm{~W} \mathrm{~cm}^{-2}$ and Al $100 \mu \mathrm{m}$ thickness and (b) $3.16 \times 10^{20} \mathrm{~W} \mathrm{~cm}^{-2}$ and $\mathrm{Cu} 25 \mu \mathrm{m}$ thickness.

ESM was placed behind the target and measured the fast electron energy spectra. Fujifilm imaging plates were used as the detectors. In spite of such broad range of conditions, only the laser intensity shows a clear dependence.

\section{EXPERIMENTAL RESULTS AND DISCUSSION}

Figure 1 shows typical signals recorded on the image plate detectors using two ESMs. The electron signal was restricted to a $5 \mathrm{~mm}$ strip by the placement of lead collimators before the entrance to the electromagnet. The background noise was estimated by measurement of the signal on the image plate adjacent to the electron signal. The short and long signals correspond to the low and high electron energies taken at two different laser intensities: (a) $6 \times 10^{18} \mathrm{~W} \mathrm{~cm}^{-2}$ and (b) $3 \times 10^{20} \mathrm{~W} \mathrm{~cm}^{-2}$. The signal was transformed from photostimulated luminescence to intensity using a standard image processing package. The intensity of the image was then converted to electron number from knowledge of the solid angle subtended from the source to detector distance (taking into account the collimator size) and calibration of the image with electron energy. ${ }^{7}$

Electron spectra measured along the laser axis are shown in Figs. 2(a) and 2(b). In Fig. 2(a) the GXII PW was used at an intensity at $6 \times 10^{18} \mathrm{~W} \mathrm{~cm}^{-2}$ on $100 \mu \mathrm{m}$ thick Al. In Fig. 2(b) the VULCAN PW was used at an intensity of 3 $\times 10^{20} \mathrm{~W} \mathrm{~cm}^{-2}$ on $25 \mu \mathrm{m}$ thick $\mathrm{Cu}$. The longitudinal axes are the electron numbers and the horizontal axes are the electron energy. The dots represent the experimental results. The measured energy spectra were fitted with an approximation of relativistic Maxwellian distribution with the electron temperature $T$ of the form ${ }^{9,19}$

$$
N(E)=N_{0} E^{2} \exp (-E / T) .
$$

Here $N_{0}, E$, and $T$ are the electron number, the electron energy, and the electron temperature, respectively. The fast electron spectra indicate good agreements with these relativistic Maxwellian distributions. A wide energy range of fast electrons may be generated at the irradiation $\operatorname{spot}^{10}$ while 

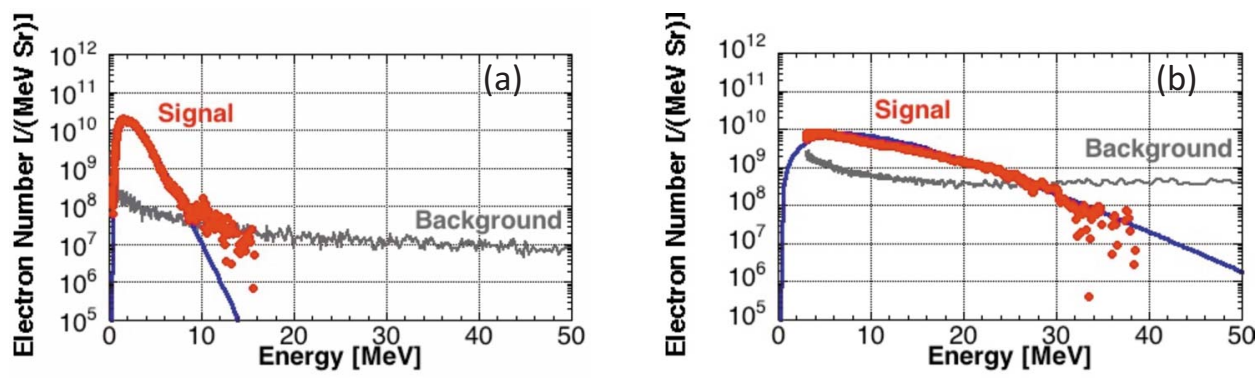

FIG. 2. (Color online) Typical calibrated electron spectra taken from the data in Fig. 1. Signals are indicated as dots. Line embedded in the signals indicates fitting with a relativistic Maxwellian equation (1). The background noise level is also indicated. those electrons are subject to the static potential formation especially of low energy less than $1 \mathrm{MeV}$. ${ }^{9}$ A warmer component is seen in Fig. 2(a). However, based on our data reduction the figure has the line of background noise level as shown in the figure. This curve may cover the warmer population appearing at above $10 \mathrm{MeV}$ in Fig. 2(a) and the data above $30 \mathrm{MeV}$ in Fig. 2(b). These components may not be suitable for the discussion. We have estimated the values taking account of the solid angle and angular divergence of fast electrons. The Vulcan case corresponds to $0.018 \%$ and the Osaka case $0.008 \%$ of conversion efficiency compared to the incident laser energy assuming an average divergence angle of $40^{\circ}$. Only small fraction of electrons can escape from the targets due to the static potential and Alfven limit. ${ }^{9}$

Figure 3 shows the measured fast electron slope temperature versus the incident laser intensity. The experimental result are compared with the Wilks' ponderomotive scaling of the form ${ }^{11}$

$$
T(\mathrm{MeV})=0.511\left(\sqrt{1+\frac{I_{18} \lambda_{\mu \mathrm{m}}^{2}}{1.37}}-1\right),
$$

where $T, I_{18}$, and $\lambda_{\mu \mathrm{m}}$ are the electron temperature, the laser intensity in units of $10^{18} \mathrm{~W} \mathrm{~cm}^{-2}$, and the wavelength in microns, respectively. The dotted line is the calculation of the

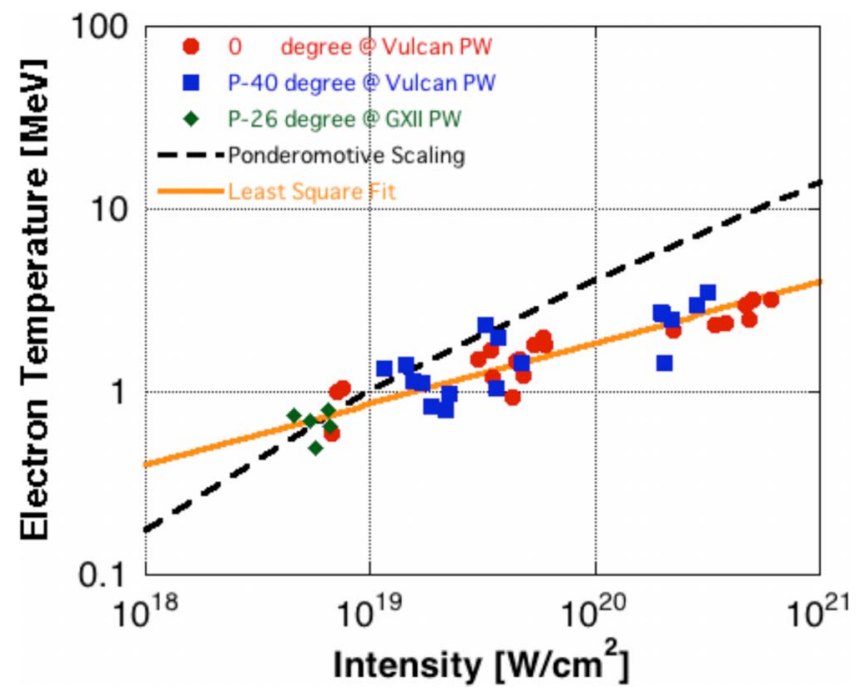

FIG. 3. (Color online) Plot of the measured electron temperature as a function of intensity on target. Also plotted is the ponderomotive potential energy as dotted line. A least square fit to the data as line shows that the fast electron temperature scales as $T(\mathrm{MeV})=0.4\left(I_{18} \lambda_{\mu \mathrm{m}}^{2}\right)^{1 / 3} \mathrm{MeV}$. electron temperature from this ponderomotive scaling. The line shows a least square fitting on the data.

In Fig. 3 the data show a clear departure from the Wilks' scaling and a good consistency with that Chen's observation of a reduction in the fast electron temperature compared with the ponderomotive potential energy is robust under a range of different irradiation conditions. In a most recent study of fast electrons measured both within targets and at ESMs show that the spectra are very much alike. ${ }^{20}$ It is of great importance to point out here that this scaling is in favor for fast ignition upcoming integral experiments; rather high irradiation laser intensity can be used to generate fast electrons within a modest slope temperature. Those experiments will use $1-10$ ps ultraintense laser pulse to fast heat a highly compressed fuel to achieve several keV core temperature. $^{21,22}$

A least squares fit to the experimental points provides almost the $I^{1 / 3}$ fit, as shown in Fig. 3, but some consideration is needed in the interpretation of this scaling. What sort of electron energy distribution is generated within the absorption region? This question is of particular concern since a number of recent computational studies have shown the fast electron spectrum softens with time. Those simulations indicate that this softening results from the preformed plasma in the corona being swept away by the ponderomotive force early in the interaction, even with picosecond duration pulses. Thereafter, the excursion distance of electrons pulled from the skin layer is much smaller than the full laser wavelength, resulting in the reduced mean energy. ${ }^{23,24}$ We believe that the main part of the acceleration is performed by the $v$ $\times B$ ponderomotive force even though we believe that our experiments suffer little effect of preplasmas. Especially the relatively long laser pulse may sweep up any plasma in front of the solid surface and then the laser starts facing its effective critical density plasma whose charge states are determined by the laser heated temperature at the area. If this situation is realized, the fast electron temperature may drop further. ${ }^{23,24}$ As discussed in several works, the prepulse may alter the characteristics of ultraintense laser matter interactions drastically. ${ }^{25,26}$ Prepulse level of this experiment can be seen in Fig. 10 in Ref. 27 which shows that the interactions should occur at the effective critical density.

To test this new understanding, simulations were performed using a new Vlasov simulation code that is one dimensional in space and two dimensional (2D) in momentum. A similar numerical approach has been used successfully to model the measured absorption fraction recently reported by 


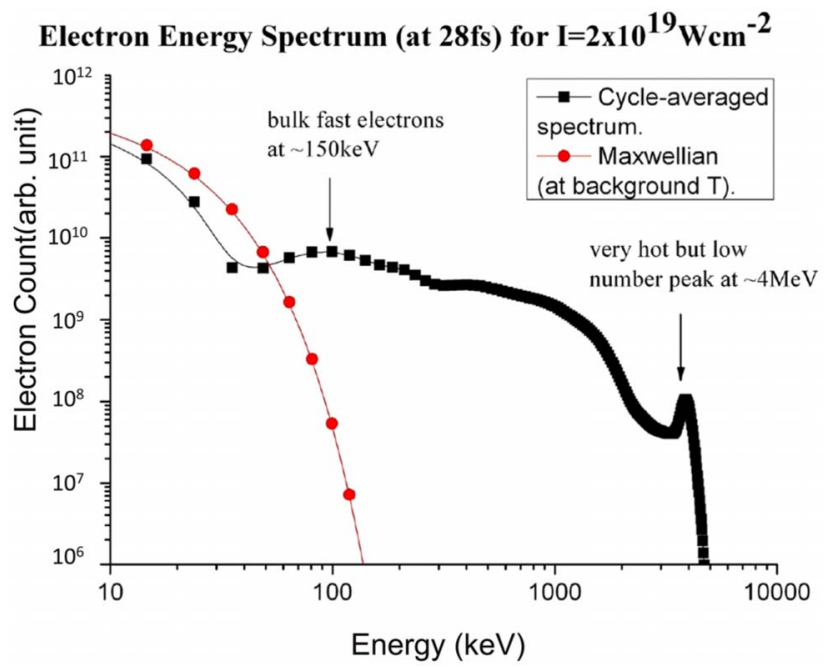

FIG. 4. (Color online) Vlasov simulations of the fast electron energy distribution calculated 28 fs into the interaction of a flat top laser pulse incident onto a plasma slab with a small density scale length. The bulk temperature is consistent with that expected with a $20 \%$ absorption fraction.

Ping et al. ${ }^{28}$ Remarkable agreement over six orders of magnitude in intensity was obtained for the absorption fraction between experiment and the modeling.

In the new simulations presented here, pulses of length of $40 \mathrm{fs}$, at an intensity of $2 \times 10^{19} \mathrm{~W} \mathrm{~cm}^{-2}$, were sent at normal incidence onto overdense plasma. While this pulse duration is much shorter than the experimental condition reported here, it does yield information on the electron distribution entering the overdense plasma that one may expect to see later in the interaction, after profile steepening has occurred. ${ }^{24}$ To mimic this steepening, the size of the plasma on the front surface of the target was much less than the laser wavelength.

The code solves the relativistic Vlasov equation for electrons and ions, coupled to Maxwell's equations for the electromagnetic field. The numerical scheme is based on Ghizzo's recent $2 \mathrm{D}$ algorithm with a novel feature for solving the electrostatic part of Maxwell's equations as an advection equation. ${ }^{22}$ The electromagnetic field is advected with cubic spline interpolation, while the distribution function is advected with a second-order flux corrected transport algorithm.

The absorption was measured in the simulations by calculating the incident and reflected Pointing fluxes. Since fast electron generation is a time-dependent process, the electron energy spectrum was time averaged over one laser period at a point $1 \mu \mathrm{m}$ inside the solid target. The simulations confirm that the bulk of the fast electrons are at a temperature of $150 \mathrm{keV}$ as shown in Fig. 4, which is significantly smaller than the ponderomotive potential energy, with a smaller number of highly energetic electrons that cutoff at $4 \mathrm{MeV}$. Of course, this is a one-dimensional simulation and an exact correspondence with experiment requires the extension to $2 \mathrm{D}$ and $3 \mathrm{D}$, which are computationally much more demanding. However, regardless of dimensionality, a mean energy value of $150 \mathrm{keV}$ is required in order to satisfy energy conservation in a good qualitative agreement with the lower tempera-

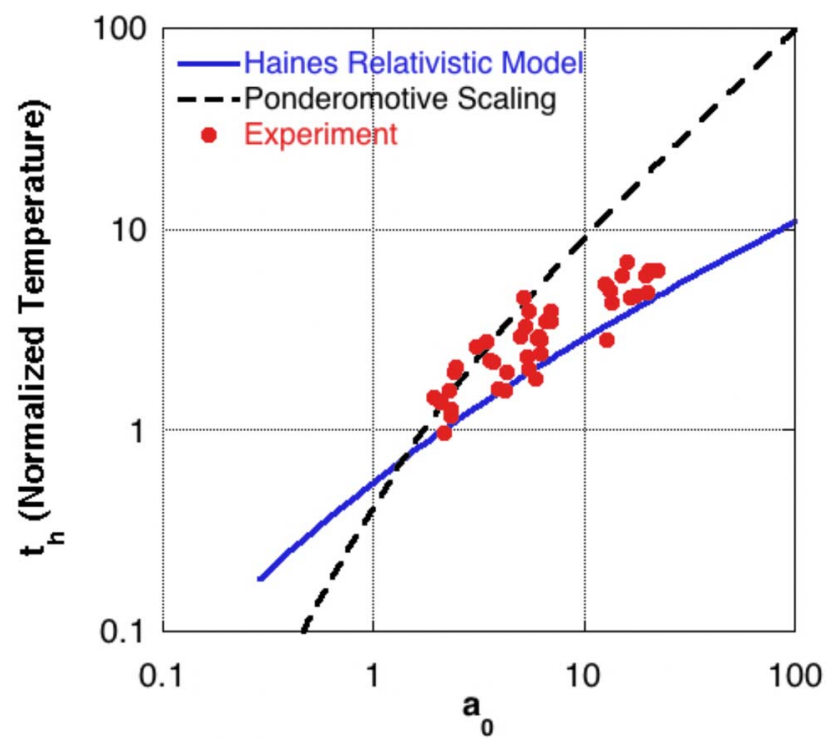

FIG. 5. (Color online) Plot of the experimental fast electron temperature (normalized to $m_{e} c^{2}$ ) vs $a_{0}$ shown as dots. Also shown is the ponderomotive potential energy as dotted line (Ref. 11) and Haines' relativistic model as line (Ref. 30).

ture scaling shown in Fig. 3. The intention is here to show that using a different computational method to particle-in-cell, ${ }^{24}$ that similar conclusions can be drawn. That is to say, as a result of profile steepening and hole boring by the ponderomotive pressure of the laser pulse, the fast electrons entering the solid density target are reduced compared with the laser pulse' ponderomotive potential energy after the preformed plasma has been removed.

A novel explanation for the $I^{1 / 3}$ intensity scaling in Fig. 3 , one that reproduces previous results up to $10^{19} \mathrm{~W} \mathrm{~cm}^{-2}$ (Ref. 29) as well as more recent bremsstrahlung radiation measurements of electron entering the target up to $10^{21} \mathrm{~W} \mathrm{~cm}^{-2},{ }^{13}$ is briefly reviewed. The laser-plasma interaction region is treated as a one-dimensional "black box," the thickness of which is a few collision less skin depths. Relativistic conservation equations are then applied to this region, rather in the same way as in a shock transition. This very simple model leads to $t_{h}=\left(1+2^{1 / 2} a_{0}\right)^{1 / 2}-1$ (Haines relativistic model), where $t_{h}$ is the normalized electron temperature, $a_{0}$ is the dimensionless magnetic vector potential associated with the laser electric field amplitude $\widetilde{E}_{0}$ which has an angular laser frequency $\omega, a_{0} \equiv e \widetilde{E}_{0} / \omega m_{e} c$. This model is discussed in detail in Ref. 30. The scaling based on the relativistic model shows very good consistency with the experiment within the laser intensity range between $a_{0}=1$ and $a_{0}=30$ (see Fig. 5 and caption).

\section{CONCLUSION}

In conclusion, the electron temperature of fast electron escaping to an electron spectrometer located on the target chamber wall has been measured for a variety of different laser conditions using two different petawatt laser facilities. These new results are consistent with both bremsstrahlung radiation measurements generated from electrons entering 
the overdense plasma ${ }^{13}$ as well as analytic models that include both energy and momentum conservation. ${ }^{30}$ It has been found that the departure from the ponderomotive scaling of the fast electron temperature as a function of intensity on target is robust and occurs under a range of different irradiation conditions. The obtained scaling gives a wider range of laser intensity window for modest temperature of fast electrons that could be utilized for designing upcoming integral fast ignition experiments compared to the one based on the ponderomotive scaling.

\section{ACKNOWLEDGMENTS}

The authors gratefully acknowledge the support of the staff of the Central Laser Facility and of Institute of Laser Engineering in the execution of this work. This work was supported by the UK EPSRC and STFC.

M.N. and R.K. were supported by the CREST, Japan Science and Technology Agency. K.A.T., H.H., and T.T. are grateful to the support from the project: global center of excellence (GCOE) at the Department of Electrical, Electric, and Information, the Graduate School of Engineering, Osaka University, Osaka, Japan and Japan-UK collaboration program of the International Collaboration for High Energy Density Science (ICHEDS) of Japan Society for the Promotion of Science (JSPS) at Osaka University, Osaka, Japan. A part of the research is supported by Grant-in-Aid for Scientific Research of JSPS (Contract No. 19206099) and by Japan/U.S. Fusion Cooperation Program (Contract No. 2036).

J.R.D. and J.V. were supported by the FCT, Grant No. POCI/FIS/59563/2004.

U.S. colleagues were supported by the U.S. Department of Energy under Contract Nos. W-7405-Eng-48, DE-FC5208NA28302, DE-FC52-92SF19460 (Office of Inertial Confinement Fusion), and DE-FC02-ER54789 (Fusion Science Center, Office of Inertial Fusion Energy Science), the University of Rochester, and the New York State Energy Research and Development Authority. The support of DOE does not constitute an endorsement by DOE of the views expressed in this article.

\footnotetext{
${ }^{1}$ M. Tabak, J. Hammer, M. E. Glinsky, S. C. Wilks, J. Woodworth, E. M. Campbell, and M. D. Perry, Phys. Plasmas 1, 1626 (1994).

${ }^{2}$ S. Atzeni, A. Schiavi, J. J. Honrubia, X. Ribeyre, G. Schurtz, Ph. Nicolaï, M. Olazabal-Loumé, C. Bellei, R. G. Evans, and J. R. Davies, Phys. Plasmas 15, 056311 (2008).

${ }^{3}$ R. Kodama, P. A. Norreys, K. Mima, A. E. Dangor, R. G. Evans, H. Fujita, Y. Kitagawa, K. Krushelnick, T. Miyakoshi, N. Miyanaga, T. Norimatsu, S. J. Rose, T. Shozaki, K. Shigemori, A. Sunahara, M. Tampo, K. A. Tanaka, Y. Toyama, T. Yamanaka, and M. Zepf, Nature (London) 412, 798 (2001)

${ }^{4}$ S. C. Wilks, A. B. Langdon, T. E. Cowan, M. Roth, M. Singh, S. Hatchett, M. H. Key, D. Pennington, A. MacKinnon, and R. A. Snavely, Phys. Plasmas 8, 542 (2001).

${ }^{5}$ G. Malka and J. L. Miquel, Phys. Rev. Lett. 77, 75 (1996).

${ }^{6}$ M. H. Key, M. D. Cable, T. E. Cowan, K. G. Estabrook, B. A. Hammel, S. P. Hatchett, E. A. Henry, D. E. Hinkel, J. D. Kilkenny, J. A. Koch, W. L. Kruer, A. B. Langdon, B. F. Lasinski, R. W. Lee, B. J. MacGowan, A. MacKinnon, J. D. Moody, M. J. Moran, A. A. Offenberger, D. M. Pennington, M. D. Perry, T. J. Phillips, T. C. Sangster, M. S. Singh, M. A. Stoyer, M. Tabak, G. L. Tietbohl, M. Tsukamoto, K. Wharton, and S. C. Wilks, Phys. Plasmas 5, 1966 (1998).

${ }^{7}$ K. A. Tanaka, T. Yabuuchi, T. Sato, R. Kodama, Y. Kitagawa, and T.
}

Takahashi, Rev. Sci. Instrum. 76, 013507 (2005)

${ }^{8}$ Y. T. Li, J. Zhang, Z. M. Sheng, J. Zheng, Z. L. Chen, R. Kodama, T. Matsuoka, M. Tampo, K. A. Tanaka, T. Tsutsumi, and T. Yabuuchi, Phys. Rev. E 69, 036405 (2004).

${ }^{9}$ T. Yabuuchi, K. Adumi, H. Habara, R. Kodama, K. Kondo, T. Tanimoto, K. A. Tanaka, Y. Sentoku, T. Matsuoka, Z. L. Chen, M. Tampo, A. L. Lei, and K. Mima, Phys. Plasmas 14, 040706 (2007).

${ }^{10}$ G. Malka, Ph. Nicolaï, E. Brambrink, J. J. Santos, M. M. Aléonard, K. Amthor, P. Audebert, J. Breil, G. Claverie, M. Gerbaux, F. Gobet, F. Hannachi, V. Méot, P. Morel, J. N. Scheurer, M. Tarisien, and V. Tikhonchuk, Phys. Rev. E 77, 026408 (2008).

${ }^{11}$ S. C. Wilks, W. L. Kruer, M. Tabak, and A. B. Langdon, Phys. Rev. Lett. 69, 1383 (1992).

${ }^{12}$ A. Pukhov, Z.-M. Sheng, and J. Meyer-ter-Vehn, Phys. Plasmas 6, 2847 (1999).

${ }^{13}$ H. Chen, S. C. Wilks, W. L. Kruer, P. K. Patel, and R. Shepherd, Phys. Plasmas 16, 020705 (2009).

${ }^{14} \mathrm{C}$. D. Chen, private communication (2008).

${ }^{15}$ C. N. Danson, P. A. Brummitt, R. J. Clarke, J. L. Collier, B. Fell, A. J. Frackiewicz, S. Hancock, S. Hawkes, C. Hernandez-Gomez, P. Holligan, M. H. R. Hutchinson, A. Kidd, W. J. Lester, I. O. Musgrave, D. Neely, D. R. Neville, P. A. Norreys, D. A. Pepler, C. J. Reason, W. Shaikh, T. B. Winstone, R. W. W. Wyatt, and B. E. Wyborn, Nucl. Fusion 44, S239 (2004).

${ }^{16}$ Y. Kitagawa, H. Fujita, R. Kodama, H. Yoshida, S. Matsuo, T. Jitsuno, T. Kawasaki, H. Kitamura, T. Kanabe, S. Sakabe, K. Shigemori, N. Miyanaga, and Y. Izawa, IEEE J. Quantum Electron. 40, 281 (2004).

${ }^{17}$ P. K. Patel, M. H. Key, A. J. Mackinnon, R. Berry, M. Borghesi, D. M. Chambers, H. Chen, R. Clarke, C. Damian, R. Eagleton, R. Freeman, S. Glenzer, G. Gregori, R. Heathcote, D. Hey, N. Izumi, S. Kar, J. King, A. Nikroo, A. Niles, H.-S. Park, J. Pasley, N. Patel, R. Shepherd, R. A. Snavely, D. Steinman, C. Stoeckl, M. Storm, W. Theobald, R. Town, R. Van Maren, S. C. Wilks, and B. Zhang, Plasma Phys. Controlled Fusion 47, B833 (2005).

${ }^{18}$ S. P. D. Mangles, C. D. Murphy, Z. Najmudin, A. G. R. Thomas, J. L. Collier, A. E. Dangor, E. J. Divall, P. S. Foster, J. G. Gallacher, C. J. Hooker, D. A. Jaroszynski, A. J. Langley, W. B. Mori, P. A. Norreys, F. S. Tsung, R. Viskup, B. R. Walton, and K. Krushelnick, Nature (London) 431, 535 (2004).

${ }^{19}$ T. W. Phillips, M. D. Cable, T. E. Cowan, S. P. Hatchett, E. A. Henry, M. H. Key, M. D. Perry, T. C. Sangster, and M. A. Stoyer, Rev. Sci. Instrum. 70, 1213 (1999).

${ }^{20} \mathrm{H}$. Habara, private communication (2008).

${ }^{21}$ K. Mima, K. A. Tanaka, R. Kodama, T. Johzaki, H. Nagatomo, H. Shiraga, N. Miyanaga, M. Murakami, H. Azechi, M. Nakai, T. Norimatu, K. Nagai, T. Taguchi, and H. Sakagami, Eur. Phys. J. D 44, 259 (2007).

${ }^{22}$ D. N. Maywar, J. H. Kelly, L. J. Waxer, S. F. B. Morse, I. A. Begishev, J. Bromage, C. Dorrer, J. L. Edwards, L. Folnsbee, M. J. Guardalben, S. D. Jacobs, R. Jungquist, T. J. Kessler, R. W. Kidder, B. E. Kruschwitz, S. J. Loucks, J. R. Marciante, R. L. McCrory, D. D. Meyerhofer, A. V. Okishev, J. B. Oliver, G. Pien, J. Qiao, J. Puth, A. L. Rigatti, A. W. Schmid, M. J. ShoupIII, C. Stoeckl, K. A. Thorp, and J. D. Zuegel, J. Phys.: Conf. Ser. 112, 032007 (2007).

${ }^{23}$ B. Chrisman, Y. Sentoku, and A. J. Kemp, Phys. Plasmas 15, 056309 (2008).

${ }^{24}$ A. J. Kemp, Y. Sentoku, and M. Tabak, Phys. Rev. Lett. 101, 075004 (2008).

${ }^{25}$ G. Malka, M. M. Aleonard, J. F. Chemin, G. Claverie, M. R. Harston, J. N. Scheurer, V. Tikhonchuk, S. Fritzler, V. Malka, P. Balcou, G. Grillon, S. Moustaizis, L. Notebaert, E. Lefebvre, and N. Cochet, Phys. Rev. E 66, 066402 (2002).

${ }^{26}$ G. Malka, N. Blanchot, D. Desenne, M. Louis-Jacquet, A. Mens, J. L. Miquel, and O. Peyrusse, J. Opt. Soc. Am. B 14, 2091 (1997).

${ }^{27}$ W. Theobald, K. Akli, R. Clarke, J. A. Delettrez, R. R. Freeman, S. Glenzer, J. Green, G. Gregori, R. Heathcote, N. Izumi, J. A. King, J. A. Koch, J. Kuba, K. Lancaster, A. J. MacKinnon, M. Key, C. Mileham, J. Myatt, D. Neely, P. A. Norreys, H.-S. Park, J. Pasley, P. Patel, S. P. Regan, H. Sawada, R. Shepherd, R. Snavely, R. B. Stephens, C. Stoeckl, M. Storm, B. Zhang, and T. C. Sangster, Phys. Plasmas 13, 043102 (2006).

${ }^{28}$ Y. Ping, R. Shepherd, B. F. Lasinski, M. Tabak, H. Chen, H. K. Chung, K. 
B. Fournier, S. B. Hansen, A. Kemp, D. A. Liedahl, K. Widmann, S. C. Wilks, W. Rozmus, and M. Sherlock, Phys. Rev. Lett. 100, 085004 (2008).

${ }^{29}$ F. N. Beg, A. R. Bell, A. E. Dangor, C. N. Danson, A. P. Fews, M. E.
Glinsky, B. A. Hammel, P. Lee, P. A. Norreys, and M. Tatarakis, Phys. Plasmas 4, 447 (1997).

${ }^{30}$ M. G. Haines, M. S. Wei, F. N. Beg, and R. B. Stephens, Phys. Rev. Lett. 102, 045008 (2009) 